\title{
Arquivos e fontes históricas sobre América Espanhola no Brasil
}

Eliane Garcindo de Sá*

\author{
Francisca L. Nogueira de Azevedo*
}

O estudo de História da América no Brasil, com raras exceções, sempre foi tratado de forma marginal em relação a outros temas de História, como conteúdos programáticos nos diferentes níveis de escolaridade. Esta constatação é fácil de verificar quando se analisa os currículos e os manuais escolares ou quando questionamos os alunos em relação ao conhecimento sobre o continente americano. É certo que nos últimos dez anos esta situação melhorou um pouco, resultado de uma política do Estado brasileiro de aproximação com as outras nações americanas, como das medidas de formação de mercado regional por parte, sobretudo, dos países fronteiriços, assim como da intensificação do turismo no continente, agregando valor ao conhecimento de línguas e culturas.

Paradoxalmente, para os mais jovens estudiosos dedicados aos temas das sociedades americanas, que já têm a referência consolidada da ANPHLAC, cujos encontros vêm reunindo número sempre crescente de participantes e de trabalhos apresentados, pode mesmo soar estranha a constatação das dificuldades que apontamos como decorrência de trabalhar com História da América, vivendo a realidade do ensino da área, como professoras do Departamento de História da UFRJ, entre os anos 80 e 90 do século passado. Éramos, na ocasião, pelo país afora, uns tantos quantos teimosos, que não perdíamos o estímulo, quando víamos, com a argumentação de falta de fontes, minguar os raros projetos de pós-graduação nessa área de estudo.

O curso de História do Departamento de História do Instituto de Filosofia e Ciências Sociais da UFRJ oferecia na sua grade curricular 4 disciplinas obrigatórias referentes aos estudos História de América, o que permitia razoáveis condições de trabalho, em comparação com a maior parte dos cursos de História.

Esse período, visto na perspectiva atual, foi frutífero na construção de alicerces que foram se constituindo nas bases que hoje se consolidam como no exemplo da

\footnotetext{
* Professora adjunta da UFRJ, aposentada; professora adjunta do Departamento de História da UERJ. Atuou no PPGHIS da UFRJ e atua no PPGHIST do curso de História da UERJ. Email: eliane.garcindo@terra.com.br

*Professora Associada da UFRJ . Atuou no PPGHIS do Instituto de História da UFRJ.
} 
atuação da ANPHLAC. É certo que as comemorações, as mais diversas e conflitantes, dos 500 anos de "descoberta" das Américas, provocaram ecos e favoreceram atividades voltadas para o tema, e os eventos de 1992 foram sendo desenhados desde alguns anos antes, facilitando apoio institucional a projetos.

Foi nesse contexto que formulamos um projeto de identificação da documentação sobre a América espanhola encontrada em bibliotecas do Rio de Janeiro, denominado Levantamento do Acervo Documental e Bibliográfico referente à América Hispânica Encontrado em Bibliotecas do Rio de Janeiro. Inicialmente, selecionamos as principais bibliotecas e as mais significativas em volume e especificidade em relação ao objeto, tais como: Biblioteca Nacional, Instituto Histórico e Geográfico Brasileiro, Biblioteca Euclides da Cunha, Academia Brasileira de Letras, Fundação Getúlio Vargas, Real Gabinete Português de Leitura e Biblioteca do Instituto de Filosofia e Ciências Sociais da UFRJ, sendo os primeiros levantamentos feitos em 1987.

Estava pressuposto o entendimento do trabalho com a documentação como provocador de visão ampliada do fato histórico, viabilizando a análise das fontes através de crítica individual, pautada em hipóteses, proporcionando diferentes interpretações do acontecimento; garantia do exercício dessa atividade fundamental, não apenas para o pesquisador, mas como elemento na formação do profissional da área. Os documentos poderiam ser também utilizados como recurso relevante na construção do pensamento analítico, que deve se desenvolver, de forma adequada, na educação básica e média. Enquanto a pesquisa bibliográfica leva o pesquisador à leitura de uma interpretação do fato, a fonte primária, de forma criativa, rejuvenesce a História. A experiência no trato da documentação torna o contato com o acontecimento do passado mais vívido e humanizado. Essas considerações justificam os objetivos e o esforço de divulgação das fontes documentais também junto aos professores e alunos do ensino médio, postulados desde o início do projeto.

Esse projeto foi se constituindo como o cerne de um grupo de trabalho, que se formalizou em 1991 como o PEA - Programa de Estudos Americanos (UFRJ) -, para o qual convergiram as atividades e desdobramentos do projeto inicial e as atividades de formação profissional, através da atuação de alunos e/ou bolsistas de Iniciação Científica, Aperfeiçoamento, Apoio Técnico e Licenciatura, algumas sob auspícios da UFRJ e outras tantas, como as de Pesquisador, para os docentes, pelo CNPq, que 
sempre apoiou os projetos e a CAPES, em ocasião de apresentação e estágio fora do país.

Nossa intenção era divulgar a documentação de duas maneiras: em forma de catálogo de referências e antologias, com foco no público universitário e escolar. Os primeiros resultados do projeto vieram com a publicação do catálogo "A Conquista do Novo Mundo: Fontes Documentais e Bibliográficas Relativas à América Hispânica" (1991) e da antologia "A Conquista da América Espanhola" (1991), ambos com a participação do Prof. Dr. Guillermo Giucci Schmidt. Outra antologia de documentos, “Antologia a Conquista da América Espanhola - Cadernos Didáticos da UFRJ" (1996) foi publicada com o objetivo de atender aos professores do Ensino Médio.

O objetivo básico do catálogo era auxiliar o historiador, facilitando, o máximo possível, sua consulta ao arquivo. Pretendia-se, antes de tudo, que o catálogo servisse como guia de investigação de um dos maiores acervos históricos sobre América hispânica. Na época que produzimos a pesquisa, o Rio de Janeiro, ao lado do México e Peru concentrava um dos três maiores acervos documentais sobre América espanhola. Já as antologias, visavam à divulgação e ao tratamento de fontes históricas. Através da apresentação da documentação, selecionada de forma temática, os docentes, tanto do ensino universitário como os vinculados ao ensino médio, poderiam tratar um episódio histórico através de fontes primárias, permitindo ao aluno contato direto com a documentação histórica.

Em virtude da quantidade de documentação arrolada decidimos, para esses dois volumes, selecionar apenas os documentos encontrados no acervo geral da Biblioteca Nacional e das Bibliotecas do Real Gabinete Português de Leitura, Fundação Getúlio Vargas, Euclides da Cunha, Academia Brasileira de Letras e do Instituto de Filosofia e Ciências Sociais da UFRJ. Era nossa intenção produzir dois outros volumes, um com a seção de "Obras Raras e Manuscritos" da Biblioteca Nacional, sem dúvida o acervo mais precioso, e outro com o acervo do IHGB. No entanto, entraves burocráticos e financeiros nos impediram de concretizar esses projetos.

É importante ressaltar, que as tarefas da descrição de fontes levam necessariamente à elaboração dos chamados instrumentos de pesquisa os quais constituem vias de acesso do historiador ao documento, sendo a chave da utilização dos arquivos fornecedores de fontes primárias para a história. Nossas preocupações se 
relacionavam, muito particularmente, com o arranjo de fontes, isto é, o processo de agrupamento da documentação é uma atividade intelectual fundamentada em bases epistemológicas. No ato de organizar uma série de documentos, estamos agindo de forma crítica sustentada por critérios previamente definidos como resultado de reflexão teórica. Deve-se observar ainda, que há diferença entre um "arranjo" produzido por critérios arquivistas, com o objetivo de organização dos acervos e os que são resultado do trabalho do historiador, visando atender aos profissionais de história. Para o historiador, por exemplo, a ordenação temática, cronológica ou geográfica atende melhor as características de seu trabalho de pesquisa. Sendo assim, durante o trabalho de definição, classificação e ordenação das fontes, não estivemos preocupados com as regras básicas utilizadas pelos arquivistas, mas sim com uma lógica de organização que atendesse melhor as especificidades da investigação histórica.

É indispensável, para quem inicia uma investigação, ter ideia clara de onde poderão ser encontrados os documentos essenciais para pesquisa e saber, ainda, qual o volume e qualidade das fontes que poderão ser utilizadas. Essas informações são fundamentais para que o pesquisador possa iniciar, com segurança, seu trabalho e, até mesmo, definir melhor seus pressupostos, pois através dos guias de fontes é possível realizar uma primeira crítica à documentação sem manusear os papéis. Na realidade, conhecer a organização geral do trabalho de classificação e os critérios de ordenação das fontes permite, principalmente, uma grande economia de tempo e de trabalho. Um arquivo se tornará melhor conhecido, agilizando o acesso às fontes, se antes de pesquisá-lo o investigador procurar conhecer guias e catálogos sobre o mesmo. Fazer a leitura dos guias dos arquivos, antes de começar o trabalho de localização das fontes, permite planificar todas as atividades de pesquisa com muito mais precisão.

Atualmente, a pesquisa na internet e a digitalização dos acervos permitem o acesso à documentação com facilidade e rapidez, mas na época em que produzimos o levantamento foi uma tarefa árdua que levou anos de pesquisa, com o apoio de vários bolsistas, em maior número os de Iniciação Científica.

Em 1992, publicamos um artigo em que apresentávamos o projeto e alguns resultados, reflexões e critérios que se definiram para organizar a documentação.

Foram relacionadas várias bibliotecas do Rio de Janeiro, considerando-se a especificidade de seu conteúdo e a importância numérica dos títulos 
encontrados. Inicialmente optou-se por concentrar as atividades nas bibliotecas mencionadas no catálogo A Conquista do Novo Mundo. O Instituto Histórico e Geográfico Brasileiro - IHGB - foi incluído posteriormente, pela relevância de seu acervo, que será (seria) divulgado em volume específico. Na verdade, a riqueza e extensão dos acervos pesquisados constituíram agradável surpresa e obrigaram os pesquisadores ao contínuo esforço de adaptar os instrumentos e o pessoal disponíveis para a execução tanto do levantamento quanto da classificação, sistematização e informatização dos dados levantados.

A organização do material obedeceu a critérios regionais e temáticos. $\mathrm{O}$ critério regional corresponde às classificações encontradas nas bibliotecas, tomando-se como padrão a Biblioteca Nacional. As regiões pelas quais se classificou os acervos são as seguintes: América Central, América Geral, América do Sul, Argentina, Bolívia, Caribe, Chile, Colômbia, Costa Rica, Cuba, El Salvador, Equador, Guatemala, Honduras, México, Nicarágua, Panamá, Paraguai, Peru, Porto Rico, República Dominicana, Uruguai e Venezuela.

A classificação temática obedece a uma cronologia tradicional: obras gerais, América Pré-hispânica, descoberta/conquista, período colonial, independência, república. Esta classificação, embora balizada por critérios impostos pela organização dos acervos, também espelha cortes decorrentes de interpretação do processo histórico feita pelos conquistadores e cronistas, e pela própria produção historiográfica.

Foram consideradas obras gerais aquelas que tratam das diferentes etapas do processo histórico na América Hispânica. América Pré-Hispânica corresponde à história das sociedades americanas até a chegada dos europeus; descoberta/conquista, ao processo de confronto que ocorres na região durante os séculos XV e XVI; período colonial é aquele onde se deu a estruturação da colonização espanhola durante os séculos XVI, XVII e XVIII; independência corresponde ao período em que se configura a crise colonial, ao final do século XVIII e no século XIX. Finalmente, a república abrange o período de formação dos Estados Nacionais, a partir do século XIX e sua trajetória pelo século XX.

As obras e os documentos levantados foram assim identificados segundo a temática, a região, a biblioteca, o autor, o registro na biblioteca, data e local de publicação. Foi esta a seqüência de dados utilizada na publicação dos resultados. ${ }^{1}$

Para que se tenha ideia do volume da documentação, apresentamos avaliação sobre a relação encontrada no catálogo para as categorias, Descoberta/Conquista e Colônia. A relação de registros para Descoberta/Conquista abrange 427 registros sendo 200 relativos à América Geral, 20 à América do Sul, 12 à Argentina, 1 à Bolívia, 3 ao Caribe, 16 ao Chile, 8 à Colombia, 2 à Costa Rica, 4 à Cuba, 2 à El Salvador, 2 ao Equador, 2 à Guatemala, 69 ao México, 17 ao Paraguai, 48 ao Peru, 6 à República Dominicana 4 ao Uruguai e 14 à Venezuela. $\mathrm{O}$ número de registros permite ainda, que se tenha dimensão das relações e interesses do Brasil com outros países latinoamericanos.

\footnotetext{
${ }^{1}$ AZEVEDO, Francisca L.N. DAYRELL; Eliane Garcindo e GIUCCI, Guillermo. "América Hispânica: documentação e bibliografia”. In: Estudo Históricos. Rio de Janeiro, vol 5 n.9 1992 p.97-105; p.98.
} 
A edição mais antiga dessa categoria data de 1784: "Recherches philosophiques sur la découverte de l'Amerique”, Joseph Mandrillon, sendo esta uma das três edições datadas do século XVIII. As publicações mais recentes datam de 1987 - por exemplo, as reedições de "Naufrágios” de Alvar Nuñez Cabeza de Vaca e os textos de Américo Vespúcio como "Novo Mundo: Cartas e Viagens Descobertas”. Do total de publicações 113 são do século XIX e 287 século XX.

Estão presentes neste acervo publicações de diversos tipos, e o material encontrado foi classificado entre os seguintes tópicos temáticos-formais: Atas de reuniões Científicas; Coleções de Documentos $^{2}$; Relatos/Diários/Cartas; Descobrimento; América: a construção; Abordagem e Representação do Índio; Igreja; América e o mundo; Conquistadores/Descobridores/Viajantes, neste tópico foi necessário abrir espaços para os registros de Cristovão Colombo e Américo Vespúcio, considerando a relevância de suas participações no processo e o teor e volume do material encontrado.

A parte relativa à Colônia foi sistematizada, como todas as outras, segundo critérios de caráter regional: América Central; América Geral (obras que abordam a História da América com um todo); América do Sul, seguindo-se indicação por país: Argentina, Bolívia, Caribe (com exceção de Cuba); Chile; Colômbia; Costa Rica; Cuba; El Salvador; Equador; Guatemala; Honduras; México; Nicaraguá; Panamá; Paraguai; Peru; Porto Rico; Republica Dominicana; Uruguai; Venezuela.

Foram relacionadas 738 obras, sendo a Venezuela o país com maior número de títulos (106) e a República Dominicana com o menor, apenas 1. Observa-se que o material sobre América Central é bem escasso. Acerca do Caribe, apenas em Cuba encontra-se número significativo de títulos (56 volumes). Em nível regional, o Cone Sul é o que contém maior concentração de volumes (178 obras). Sem dúvida, para esta categoria, o acervo da Biblioteca Nacional é o maior (530 títulos) tanto quantitativa quanto qualificativamente.

A guisa de exemplo, selecionamos, dentro de um dos volumes de Coleção de Documentos, o conjunto intitulado, "Correspondencia de la Ciudad de Buenos Ayres con los Reys de Espanha - Cartas del Cabildo-Memoriales Apresentados en la Corte

\footnotetext{
${ }^{2}$ Como exemplo dessas coleções temos: "Colección de Documentos Inéditos, Relativos al descobrimiento, Conquista y Organización de las Antiguas Posesiones Españolas de América y Oceania”, de 1864.
} 
por los Procuradores, Apoderados y Enviados especiales de Ciudad (1508-1615)". O conjunto contém 21 cartas. As primeiras datam do século XVI (duas de 1588 e uma de 1598) e informam sobre o despovoamento da "gente do porto para dar razão aos que vinham da Espanha" e fazem referência às atividades de Juan de Salazar em favor da coroa espanhola, nas províncias do Rio da Prata. Encontra-se ainda, neste volume, um bloco de correspondência da província de Santa Fé, assinadas por Juan de Garay, fundador de Buenos Aires, narrando seu trabalho na região e pedindo ajuda e envio de sacerdotes.

A correspondência do início do século XVII é, em parte, resposta à coroa sobre os pedidos anteriores. O Cabildo agradece ao rei a ajuda concedida através da Real Fazenda no Potosí e a permissão para o comércio no Rio da Prata. Reitera o pedido de envio de homens para defesa da cidade. A última carta do procurador-geral de Buenos Aires ao Rei é datada de 1616, e revela o pedido de doações e aquisição de escravos negros. A intensa atividade comercial de portugueses na região gerou o "sistema" Brasil-Rio da Prata, duas zonas produtivas que se complementavam. Os portenhos exportavam farinha de trigo, charque e sebo em troca de escravos comercializados pelos portugueses.

O que se conclui da leitura da correspondência desse período é a experiência de acelerado desenvolvimento urbano e econômico do litoral, tornando urgente a defesa da região rio-platense, dada a sua vulnerabilidade ante o interesse de outras nações estrangeiras. O que as autoridades locais queriam era a realização de um grande empreendimento militar e naval no Prata e, ao mesmo tempo, uma política econômica que proporcionasse os recursos necessários para a implementação das estruturas fundamentais de defesa da região.

A apresentação e o tratamento desse conjunto de documentos pretende evidenciar, além da estrutura de organização, que se manteve, mesmo em relação aos conteúdos dos acervos não publicados, o potencial dos registros do acervo. Talvez um pouco óbvias, essas informações ainda podem ser úteis para as primeiras abordagens aos arquivos. Mesmo os arquivos digitalizados observaram as estruturas de organização do material encontradas nos registros físicos que lhes serviram de referência.

A relevância e a especificidade do acervo do IHGB referente à América Hispânica, como já se observou, impuseram a urgência da sua inclusão ao projeto 
original. Para melhor exemplificar o tipo de trabalho que realizamos, decidimos selecionar, para este texto, uma breve apresentação e comentário desse acervo. A riqueza documental americanista que o IHGB oferece torna-o um centro referencial necessário para pesquisa sobre América Espanhola. É um dos maiores e talvez o mais valioso conjunto documental que podemos encontrar sobre o assunto, especialmente quando nos referimos à região do antigo Vice-Reino do Rio da Prata. Para qualquer investigação sobre história dessa região, é necessário que se consulte este acervo.

A documentação sobre América hispânica é de origem escrita, impressa, iconográfica e cartográfica. Incluiu livros nacionais e estrangeiros contabilizando um acervo com total de 3530 títulos. Os documentos em sua maioria datam do século XVIII e XIX. Inclui várias obras de referência como dicionários geográficos e biográficos; coletâneas documentais, que tratam em geral de papéis referentes ao processo de independência da América, principalmente sobre a região do Rio da Prata, como Atas de Cabildos e Audiências e Memórias das principais lideranças. Particularmente sobre a "Revolução de Maio", considerada pela historiografia argentina um marco no processo revolucionário, encontramos trinta e oito títulos compostos por conjunto de documentos, obras impressas e biografias. O IHGB contém grande parte da documentação selecionada e publicada pelo Museo Historico Nacional da Argentina.

A histórica diplomática tem lugar privilegiado, talvez por contar o Instituto entre seus membros com vários diplomatas historiadores ou historiadores interessados em política externa como: Francisco Adolfo Varnhagem, João Pandiá Calógeras, Caio Freitas, Arthur Renato da Rocha, entre outros. As questões sobre Colônia do Sacramento e Guerra Cisplatina contam com enorme variedade de documentos, especialmente correspondências do Visconde, Barão e Marquês do Herval, Visconde de Tamandaré, Marques de Caxias, etc.

A Coleção General Osório é especialmente importante, pois abriga grande diversidade e quantidade de fontes sobre a Guerra do Paraguai, mas também as correspondências do General Osório à família o que permite reconstituir o cotidiano e as particularidades dos acampamentos de guerra. Pode-se encontrar nos fundos dessa coleção não somente correspondências públicas e privadas, mas ofícios, memorandos entre oficiais e/ou entre os chefes militares e os respectivos governos, como até o interrogatório dos prisioneiros de guerra e estratégia de combate. 
O conjunto de documentos pessoais do arquivo General Osório que se compõe de 50 cartas, entre ofícios, memorandos, etc., é de grande relevância. Selecionamos algumas cartas para que o leitor possa ter noção da importância do acervo e especialmente da correspondência para o estudo da História. É importante ressaltar aqui, que a correspondência adquire estatuto de documento histórico, uma vez que a leitura das cartas permite observar muitas das transformações políticas e sociais do período em que são escritas. O tempo real permite a identificação histórica dos fatos e personagens, enfatizando a dimensão individual desse processo.

No ano em que o General Osório escreve as cartas - 1867 - o exército aliado passa momentos difíceis, em virtude da crise política gerada pela derrota na Batalha de Curupaiti, considerada a pior derrota da guerra. Um mês depois da derrota, outubro de 1866, Bartolomeu Mitre, então presidente da República Argentina, passa o comando das forças aliadas ao Marechal Luis Alves de Lima e Silva, então Marquês de Caxias.

Após a Batalha de Curupaiti, aliados e paraguaios permaneceram entrincheirados por quase um ano. Osório escreve diariamente para esposa, e de forma quase jornalística, narra o desenrolar dos acontecimentos, que na verdade é a expressão de uma visão particular da guerra: ${ }^{3}$

...A 25 de M.ço passei o uruguai vamos sem novidade e tive notícias do Sr. Caxias...No dia três do mes de abril dois mil homens da cavalaria inimiga a força que temo em São Solano o inimigo foi completamente derrotado deixando no campo quinhentos mortos e 92 feridos inclusive o major Dinart...porem tudo ia bem por ca...o Visconde de Porto Alegre mandando a 24 de abril uma força atacar outra maior do inimigo sofreu afinal uma perda de quarocentos homens fora de combate e neça foi morto o major Vasco e...... Astrogildo....A cavalaria do inimigo esta muito mal montada o velho coronel Fernandez foi eroi do dia 3 de abril.

O general menciona Caxias sem muito entusiasmo:

O Marques de Caxias anda tao agil como nunca o vi a ultima derrota que o inimigo sofreu em 2000 homens de cavalaria deve ter incomodado Lopez porque foi na sua melhor tropa que é cavalaria e deixou em noço poder mortos e prisioneiros mais de 600 homens.

${ }^{3}$ Conjunto de citações a seguir disponíveis em: Coleção General Osório, IHGB. DL226.16/226.17/226.18 
As vitórias das forças aliadas animam o General e, mesmo ferido na perna, não quer deixar o "teatro da guerra”: “...não fui a Montevideo, Buenos Aires ou Corrientes tendo voltado ao teatro da Guerra e trazendo ainda 4 mil patricios não tenho animo para os deixar, porem se o mal se agravar procurarei riforços..."

Grande parte da correspondência, mesmo quando dirigida à família, tem como assunto o conflito. Talvez a escrita lhe permitisse refletir sobre as estratégias de combate e avaliação do exército inimigo:

...muito risco esta posta o citio a Lopez mas par isto tem avido alguns combates sanguinolentos o inimigo foi atacado no 1.0 e 2.0 do Com...em Priero Ovelha contra o Rio Paraguai pelo norte de Humaita o inimigo perdeu dois vapores e setecentos homens nos tivemos ali quatrocentos fora di combate a maior parte ferido...

Descreve detalhes do ocorrido no campo de batalha, permitindo ao leitor acompanhar o cotidiano da movimentação das tropas:

\begin{abstract}
...no dia 3 uma força inimiga atacou de surpresa o Porto (...) e podi entrar nas trincheiras de Tuyuti pelo lado dos argentinos (...) ..comandado pelo navio Brigada Vitorino e então o inimigo foi reforçado, tivemos 800 homens fora de combate e o inimigo ...Lopez quis por em condições di vencedor.... Os paraguaios parecem algo acovardados depois que começamos as operações temos lhe morto 7000 homens e tido fora de combate 50 pouco mais ou menos e muita fortuna a noça esquadra anda bombardeia Humaita porem creio q. por ali não paça por q. não e possivel e só por um citio se vencerá entretanto lhe são distroçados sempre q.saem a сатро...
\end{abstract}

A correspondência permite ao leitor acompanhar um dos momentos mais críticos do conflito e seu desenlace. Em carta de 13 de abril, General Osório começa anunciar a paulatina derrota das forças paraguaias:

\begin{abstract}
... o inimigo foi rechaçado deixando dois mil e tresentos mortos porem tem tempo di roubar o que pode... surpreendido Lopez esta a tres dias reduzindo as suas trincheiras...Humaitá esta muito estragado di noças bombas da esquadra ... No dia 29 escreve: depois do ataque de 3 (...) cavalarias com as do inimigo tivemos outro a 21 e no q.al o inimigo teve for a di combate como mil homens deixando no campo mortos mais de 500, afim e q. as nossas com. as do $2^{\circ}$ e $3^{\circ}$ corpos de exército tem continuado feliz.
\end{abstract}

Por meio desses depoimentos, Osório nos permite entender a guerra a partir de sua experiência no campo de batalha, os momentos de maior tensão e a avaliação sobre 
a perspectiva do evento. A análise das cartas no âmbito familiar é quase invasão da privacidade do casal e da família. Esse é um outro viés que se abre para a visão do quotidiano, das relações familiares. A correspondência também, sobretudo no seu conjunto, oferece registro significativo da avaliação e das representações dos diferentes papéis e funções desempenhados durante o conflito, pelo olhar do emissor. Igualmente, se constitui uma visão do "outro", no caso dos inimigos e aliados.

Observa-se que os problemas com a fronteira sul são vastamente documentados contando tanto com papéis referentes aos conflitos quanto como os relativos às demarcações de fronteiras e tratados de limites desde os primórdios da colonização.

As obras impressas do IHGB, em sua grande maioria, fazem parte da historiografia produzida entre os anos vinte e cinquenta do século $\mathrm{XX}$, realizadas geralmente por intelectuais influenciados pela tradição historiográfica liberal que incentivou a produção de Histórias Nacionais ou biografias sobre os "construtores" da nação. Grande parte do acervo sobre América espanhola foi resultado de um acordo, nos anos 40 do século passado, entre os Institutos Históricos da América Latina, visando o intercâmbio de documentos.

No formato que definimos para a divulgação do material, após a apresentação geral do acervo, o catálogo trazia a listagem da documentação selecionada por ordem temática e geográfica, mas mantendo a classificação definida pela organização do arquivo. Dessa forma, o pesquisador rapidamente chegava aos documentos referentes à sua pesquisa.

Embora não tenha sido objeto de nossa pesquisa, vale lembrar que a Revista do IHGB, também é depositária de considerável número de ensaios e artigos sobre a América Hispânica, tornando-se assim elemento essencial para a investigação sobre o tema. Por outro lado, além das bibliotecas citadas não podemos esquecer, de consultar para diferentes temas sobre América espanhola, particularmente o século XIX, os Arquivos do Itamaraty e o arquivo Histórico do Museu Imperial em Petrópolis.

Apesar de interrompida, a publicação dos resultados do projeto, talvez desprovida atualmente de sentido, tendo em vista novos recursos tecnológicos na área da informática, o referido projeto constituiu parte de um esforço de construção e reconhecimento de um campo de estudos que vem crescendo e que vem revelando outros acervos pelo país afora. Enquanto estivemos desatentos para os temas pertinentes 
a esse universo de estudo que chamamos História da América, muitos registros nos passaram despercebidos. O levantamento dos acervos tornou evidente que havia disponibilidade de recursos para as pesquisas. Por certo, a cidade do Rio de Janeiro, por condições específicas, concentrou grande parte de fontes documentais e bibliográficas sobre esses temas, mas há muito a localizar e identificar em acervos locais e mesmo particulares. Há uma grande e estimulante tarefa para tantos pesquisadores que agora podem contribuir, de tantos pontos geográficos, mas articulados por interesses comuns, numa rede que se amplia constantemente na direção de um conhecimento mais rico, diversificado e agregador entre as sociedades na América.

\section{Referências Bibliográficas:}

ABELLÁn, Jose Luis. La idea de América. Origen y Evolución. Madrid, Istmo, 1972.

AZEVEDO, Francisca Nogueira. Fontes para o Estudo da América Espanhola: período colonial. In: AZEVEDO, Francisca Nogueira \& MONTEIRO, John Manuel (org.). Raízes da América Latina. São Paulo, Expressão e Cultura: EDUSP, 1996; pp.87-101.

AZEVEDO, Francisca L. N., DAYRELL, Eliane Garcindo, SCHMIDT, Guillermo Giucci. A Conquista do Novo Mundo: Fontes Documentais e Bibliográficas Relativas à América Hispânica . Rio de Janeiro, FUJB, 1991.

A Conquista da América Espanhola: Antologia. Rio de Janeiro,

FUJB, 1991.

América Hispânica: documentação e bibliografia. In: Estudo Históricos, Rio de Janeiro, vol 5 n.9 .1992 p.97-105.

AZEVEDO, Francisca L. N. e DAYRELL, Eiane Garcindo (orgs.). Antologia A conquista da América Espanhola. Rio de Janeiro: Editora da UFRJ, Cadernos Didáticos 27, Coleção América, 1996. 
BELlOTO, Heloisa Liberalli. Arquivos Permanentes: Tratamento Documental. São Paulo, T. A. Queiroz Editor,1991.

CASTILlO, Guillermo Céspedes del. Textos y Documentos de la América Hispánica (1492-1898). Barcelona, Editorial Labor, S.A., 1988.

CONTI, Simonetta. Un Seccolo di Bibliografia Colombiana, 1880-1985. Genova, Casa di Risparmio di Genova e Imperia. 1986.

DAYRELL, Eliane Garcindo Fontes para o Estudo da América Espanhola: descoberta/conquista. In: AZEVEDO, Francisca Nogueira \& MONTEIRO, Jonh Manuel (org.). Raízes da América Latina. São Paulo, Expressão e Cultura: EDUSP, 1996; pp.75-85.

FENELON, Déa Ribeiro. Fontes para o Estudo da Industrialização no Brasil (18891845) In: Revista Brasileira de História, 2, 3, mar. 1982, p.79-115.

FRIEDERICI, Georg. El Caráter del Descubrimento y de la Conquista de América. México, Fondo de Cultura Económica, 1973.

KONETZKE, Richard. América Latina. La Época Colonial. 18ed., México, Siglo Veintiuno, 1986. 